\title{
Greenhouse gas mitigation potential of annual and perennial dairy feed crop systems
}

\begin{abstract}
Dairy production constitutes a significant amount of the total global anthropogenic greenhouse gas (GHG) emission. One of the proposed strategies to mitigate GHG emission from dairy production is by enhancing soil carbon sequestration through promoting the growing of perennial over annual dairy feed crop. We determined the net ecosystem carbon budget (NECB) of a hay and corn field grown side-by-side over three years to compare the GHG mitigation potential of perennial over annual feed crops in Elora, Ontario, Canada. The NECB was determined using measurements of net ecosystem exchange (NEE), total plant carbon content, and carbon content in applied dairy manure. The greenhouse gas balance (GHGB) were determined using the NECB plus the total nitrous oxide (N2O) fluxes measured by a complementary study at the same site. The effect of plowing of the hay field on the NECB and GHGB was also investigated. Our observations indicate that on average over the three study years, NECB of hay $\left(7 \pm 51 \mathrm{~g} \mathrm{C} \mathrm{m}^{-2} \mathrm{yr}-1\right)$ was significantly lower than corn (154 $\left.\pm 79 \mathrm{~g} \mathrm{C} \mathrm{m}^{-2} \mathrm{yr}-1\right)$ indicating that corn was a larger carbon source than hay. The three-year average GHGB of 796 and $127 \mathrm{~g} \mathrm{CO} 2$-eq $\mathrm{m}-2 \mathrm{yr}-1$ for corn and hay, respectively, indicated that corn was a larger emitter of GHG than hay. The NECB was the more dominant factor than $\mathrm{N} 2 \mathrm{O}$ emissions in influencing the outcome of the annual GHGB. We conclude that hay has a larger potential than corn in sequestering carbon and mitigating GHG emission even when emissions from hay plow-down are included.
\end{abstract}

Keyword: Net ecosystem carbon budget; Greenhouse gas balance; Greenhouse gas mitigation; Annual; Perennial; Corn; Hay; Dairy feed 